\title{
GRANDES ESTRATEGIAS Y PEQUEÑAS INTRIGAS: GÉNOVA Y LA MONARQUÍA CATÓLICA DE CARLOS V A FELIPE II
}

\author{
por
}

\section{ARTURo PaCinI}

Universidad de Pisa

RESUMEN: La estrategia de Carlos V y Felipe II en el Mediterráneo tenía un punto básico en la alianza con Génova, por la cual estos monarcas aceptaron y sostuvieron el régimen republicano deseado por Andrea Doria en 1528. Desde entonces se consolidó una fuerte relación consistente en un intercambio político: fidelidad de Génova a España en su lucha con Francia a cambio de la protección española a la libertad de la república. La fidelidad de Génova a los Austrias se manifestó principalmente en la prestación de dos servicios clave: la armada genovesa y el crédito de sus banqueros. Este lazo simbiótico atravesó una crisis en 1575 a causa de una revuelta interna que unió a la llamada nobleza nueva con el pueblo contra la conocida como nobleza vieja (aliados tradicionales de España). Se examina aquí la contradictoria política de Felipe II con respecto a la revuelta genovesa y los mecanismos de toma de decisión que llevaron a la corte de Madrid a conceder, por un lado, licencia a la nobleza vieja para iniciar una guerra privada contra la república y, por otro, suspender el pago de sus créditos a esta misma nobleza.

Palabras Clave: Génova. Monarquía Hispánica. Andrea Doria. Revuelta de 1575 . Nobleza Vieja. Nobleza Nueva. Felipe II. Banqueros.

ABSTRACT: One of the fundamental points in Charles V's and Philip II's strategy in the Mediterranean area was the alliance with Genoa; in order to maintain this alliance, they accepted and supported the republican regime desired by Andrea Doria in 1528. From that moment on a strong and reciprocally useful relationship developed and was consolidated. It consisted in an eminently political exchange: loyalty for protection - Genoa's loyalty to Spain in the great struggle with France; protection and safeguarding of the city's liberty on the part of the Spanish Monarchy. Genoa's promise of loyalty to the Habsburgs could be seen principally in the fact that it put at their disposal services in two key sectors: ships and credit. This symbiotic link risked collapse in 1575 because of an internal revolt in Genoa 
that united the «new» nobles and the «people» against the «old» nobles (traditionally allied with Spain). This paper examines Phillip II's contradictory policy awards the Genoese revolt, and the mechanism of decision making that led the court of Madrid to choose simultaneously to suspend the repayment of the "old" nobles' credits to the Monarchy and to allow them to begin a private war against the republic.

KEY WORDS: Genoa. Hispanic Monarchy. Andrea Doria. 1575 Revolt. Old Nobility. New Nobility. Phillip II. Bankers.

\section{GÉNOVA EN LA ESTRATEgIA MEDITERRÁNEA DE LOS AUSTRIAS}

Recientemente Geoffrey Parker ha propuesto la idea de una «gran estrategia» de Felipe II como un conjunto de principios prioritarios concernientes a la estructura geopolítica del imperio español, capaz de jerarquizar las emergencias de naturaleza casi siempre militar, a menudo concomitantes en áreas distintas, y que estaría en la raíz de las decisiones de la Monarquía Católica a la hora de dirigir hacia este o aquel teatro de operaciones bélicas hombres, medios y recursos. Parker individualiza tales principios en formulaciones muy generales, y distingue las de naturaleza religiosa (defensa del catolicismo, justificación teológica y ética, providencialismo, reputación) de las político-militares (actitud defensiva, inalienabilidad de las tierras patrimoniales, jerarquía de las prioridades territoriales, teoría del dominó, carácter inevitable y en un cierto sentido deseable de conflictos regionales, solidaridad con la rama austriaca de los Habsburgo). Formulaciones tan imprecisas que en algunos casos resultan difíciles de traducir en decisiones operativas concretas. La complejidad de los problemas que Carlos V y Felipe II tuvieron que afrontar parece resistirse a la instancia racionalizadora del historiador, sin que, por otro lado, esto legitime una interpretación de su política como estructuralmente confusa, basada «en el correo de la mañana», o condicionada (en el caso de Felipe II) por la hipoteca de una «aritmética de distancias desfavorable» 1 .

Si pasamos del resbaladizo terreno de la gran estrategia a las estrategias de área, y en especial a Italia y al Mediterráneo, resulta evidente la progresiva formación de una especie de doctrina defensiva, con tendencia a coordinar las funciones de los diversos dominios españoles en la península con relación a la salvaguardia del edificio imperial en su conjunto ${ }^{2}$. Esta doctrina era fruto de la

1 GonZÁlez de LeÓN, F., PARKer, G.: «The Grand Strategy of Philip II and the Revolt of the Netherlands, 1559-1584» en BeNEDiCT, P., MARNeF, G., VAN NieroP, H., VeNARD, M. (eds.): Reformation, Revolt and Civil War in France and the Netherlands, 1555-1585, Amsterdam, 1999, pp. 215-232 (edición española en RuBOT GARCíA, L. A. (ed.): Felipe II a debate, Madrid, 2000, pp. 41-61), y PARKER, G.: La gran estrategia de Felipe II, Madrid, 1998 (edición inglés, New Haven-London, 1998).

2 Cf., por ejemplo, Ribot García, L. A.: «Las provincias italianas y la defensa de la Monarquía», en MUSI, A. (ed.): Nel sistema imperiale. L'Italia Spagnola, Nápoles, 1994, pp. 67-92, IDEM: «Milán, plaza de armas de la Monarquía», en De MadDalenA, A. (ed.): Millain the great. Milano nelle brume del Seicento, Milán, 1989, pp. 349-363 y en Investigaciones Históricas, (Valladolid) 10 
sedimentación de discursos e interpretaciones sobre los acontecimientos políticomilitares de la región a partir, al menos, del inicio de las guerras de Italia y tenía uno de sus puntos focales en el papel otorgado a la ciudad y república de Génova. De otro modo, no se explica la afirmación realizada por el duque de Alba en una reunión del Consejo de Estado en diciembre de 1575 cuando una revuelta antinobiliaria estaba poniendo en peligro los ya tradicionales lazos de la ciudad ligur con la monarquía española: «Dixo primero que los negocios de estado tenían unas máximas y principios, como otras sciencias, los quales no se ponían jamás en disputa, y que assí en este negocio de Génova, desde que él tratava negocios, era una admitida de todos los que les avían tratado en su tiempo: aver menester su magestad tener a Génova para conservar los estados de Italia» ${ }^{3}$ en primer lugar el ducado de Milán.

Es fácil encontrar confirmaciones a esta apreciación. Ese mismo año, y por los mismos motivos, un informador habitual infiltrado en la embajada francesa en Madrid hacía remontar al «parescer de Prospero Colona y del marques del Vasto» (es decir, en los años veinte del siglo XVI) la idea de «que el govierno de Milán no se puede conservar sin tener el govierno de Génova», y por esto aconsejaba a Felipe II que se apropiara «avierta o secretamente» de la repúbli$\mathrm{ca}^{4}$. Estas formulaciones tienen su origen en el antiguo adagio Ianua ianua Italiae, ampliamente difundido entre los historiadores y los políticos de los siglos XV y principios del XVI, que condensa uno de los motivos que hicieron de la ciudad ligur una especie de primera línea en el enfrentamiento entre las grandes monarquías por el predominio en la península: el hecho de constituir un objetivo estratégico en cuanto única vía de conexión entre el Tirreno septentrional y la Lombardías. Podemos reconstruir las principales etapas en las que se consolidó una valoración del aporte potencial (y después efectivo) de Génova a la hegemonía europea de España. Un proceso que, a veces, estuvo conectado con determinados momentos críticos de los reinados de Carlos V y de Felipe II.

En 1522, al comienzo del conflicto entre Francia y el Imperio en Italia, Génova fue arrebatada violentamente al dominio del rey de Francia y, como república libre, entró a formar parte del frente filoimperial. Comenzaron entonces los considerables aportes financieros de los mercaderes-banqueros ligures a Carlos V, en cuya base existía una antigua y fuerte presencia de las prin-

(1990) pp. 203-238, Ruzzo, M.: «Centro spagnolo e periferia lombarda nell'impero asburgico tra Cinque e Seicento", en Rivista Storica Italiana, (Turín) CIV/2 (1992) pp. 315-348.

. 3 Archivo General de Simancas (desde ahora AGS), Estado 1408, f. 227, Consejo de Estado del 19 de diciembre de1575.

4 AGS, Estado K1538, f. 107, «Lo que al presente paresce que su magestad podrá hazer para assegurar sus estados de Flandes y de Italia».

5 Cf. BORLANDI, A.: «'Janua, janua Italiae': uno sguardo al Quattrocento genovese», en $\mathrm{Ar}$ chivio Storico Italiano, (Florencia) CXLIII/1 (1985) pp. 15-37, y PACINI, A.: I presupposti politici del "secolo dei genovesi»: la riforma del,1528, en Atti della Società Ligure di Storia Patria, (Génova) n.s., XXX (1990) pp. 49-51. 
cipales casas comerciales genovesas en los reinos ibéricos ${ }^{6}$. $\mathrm{Al}$ año siguiente llegó a la ciudad Lope de Soria ${ }^{7}$; el primero de una larga serie de delegados españoles que harían de la embajada de Génova uno de los núcleos fundamentales de la red diplomática de la Monarquía Católica en Italia. Los análisis de Soria constituyen una de las primeras formulaciones de un tipo de pensamiento estratégico que acabaría por convertirse en patrimonio común. Ya entonces, el lazo entre la ciudad ligur y España parecía esencial pero también tenía aspectos contradictorios destinados a perdurar en el tiempo. Por un lado se daba por descontado que, como escribiera Soria a Carlos V poco después de la estrepitosa victoria de los imperiales en Pavía a mediado de los años veinte: «podrán dezir algunos que teniendo los ginoveses tantos bienes en los reynos y señorías de vuestra magestad, no osarían hazerle ningún desservicio, pues podría castigarlos con mucho daño dellos». Se trataba de un razonamiento basado en la palmaria asimetría entre el potencial militar de ambos estados, y en la imponente entidad de los bienes poseídos por los genoveses en tierras ibéricas, situación que permitía a los Habsburgo disponer de un enorme poder de chantaje. Por lo que, seguía Soria: "Yo respondo que toda Génova no vale tanto como sería el daño que vuestra magestad podría recebir en caso que ellos se reboltassen para desservirlo». Además actuar sobre las «haziendas» de los ligures asentados en España habría sido inútil, porque «el daño no se podría escusar» ${ }^{8}$. El significado implícito quedaba claro: la unión con los genoveses (ya que los servicios que eran capaces de proveer eran tan grandes como los daños que podían causar) no se podía concebir como una relación de mera dependencia.

El aporte de Génova para la puesta en práctica de los objetivos de la monarquía se puso de manifiesto durante el último periodo de dominio francés, de agosto de 1527 a septiembre de 1528. No olvidemos tampoco que los éxitos imperiales en Italia hasta la batalla de Pavía se habían conseguido también gracias al crédito de los mercaderes-banqueros ligures. Una vez que la ciudad estuvo bajo control de Francisco I, la red financiera que había garantizado la transferencia de los recursos a las áreas de operaciones militares sufrió un violento contragolpe.

El mecanismo, ágil y funcional hasta que Génova fue su eje, se volvió poco fiable, y acabó por bloquearse. Tener dinero fresco en Italia se había convertido en «el mayor travajo del mundo». Soria lo había previsto, y consideraba la liberación de Génova como el objetivo prioritario de la política imperial, "porque es la puerta y llave de Italia, y por donde se da forma de aver dineros y avisos y

6 Baste citar OTTE, E.: «Il ruolo dei Genovesi nella Spagna del XV e XVI secolo», en DE MADDALENA, A., KellenBenZ, H. (eds.): La repubblica internazionale del denaro, Bolonia, 1986, pp. 17-56.

7 Sobre Soria cf. Pizarro Llorente, H.: «Un embajador de Carlos V en Italia: don Lope de Soria (1528-1532)» en MARTíneZ MiLlán, J. (ed.): Carlos $V$ y la quiebra del humanismo político en Europa (1530-1558), Madrid, 2001, IV, pp. 119-155.

8 Carta del 5 de abril de 1525, Real Academia de la Historia, Madrid, Colección de don Luis Salazar y Castro (desde ahora RAHM, CSC), ms. A-34, cc. 220-226. 
fuerças de armada de mar»9. Ubicación estratégica, abundantes reservas financieras y disposición para emplearlas en los mercados de cambio, capacidad de construir y armar galeras por cuenta de otros constituyen, en suma, una serie de características propias de Génova que condicionaron para bien y para mal su historia en los primeros siglos de la Edad Moderna. Por un lado la pusieron en el centro de la contienda por la supremacía en Italia y en Europa y, por otro, fueron la causa de su fortuna.

Lo que la ciudad ligur podía ofrecer convertía su alianza en algo muy útil para Carlos V. Fue en buena parte Andrea Doria el que resolvió los graves problemas del Emperador en el frente mediterráneo a finales de los años veinte. Después de pasar con sus galeras en agosto de 1528 del servicio del rey de Francia al de los Habsburgo, Doria dio una contribución esencial a la quiebra de la empresa de Lautrec en el reino de Nápoles y expulsó a los franceses de Génova. Apoyó además la elaboración final de un texto legislativo (las Reformationes Novae) que fundaba sobre nuevas bases las instituciones ciudadanas y cambiaba la estructura misma de la clase de gobierno, eliminando las tradicionales divisiones faccionarias y creando un único orden de ciudadanos nobles. Obviamente, la nueva república se puso de lado de su libertador ubicándose junto a Carlos $\mathrm{V}$ en el ámbito internacional.

La base de la duradera unión entre Génova y España la encontramos en el primer artículo del asiento entre el almirante y el emperador:

«Primo domanda [Andrea Doria] a sua cesarea maestà che sempre che gli sia concesso gratia da Dio di levare Genova da lo soggieto de soi inimici, sia posa in libertà soa, et remessa a vivere in forma de republica, et reintegrata de tutto il suo dominio et specialmente della terra de Savona, della quale conservatione, senza altro pagamento né graveza di quella che la cità vorrà cortesemente dare, ne permetta la protetione, et ordini et comandi a tutti li soi capitanei in Italia che la conserveno et deffendano da ogni forzo et violentia de chi la volesse perturbare» 10 .

Por la firma de este contrato, Carlos V se comprometió a favorecer la vuelta de Génova a su antigua libertad, a velar por la recomposición de su dominio territorial, y a protegerla de sus enemigos. En base a estos presupuestos se consolidó una relación fuerte y recíprocamente provechosa entre la ciudad y el Emperador. Una relación que quedó como una preciada herencia para los suce-

9 Carta a Mercurino da Gattinara del 17 de junio de 1528 (RAHM, CSC, ms. A-42, c. 425), y a Carlos V del 17 de septiembre de 1527, Biblioteca Nacional de Madrid, ms. 20214 ${ }^{62}$, n. 15. Para las dificultades financieras causadas a los Habsburgo por la pérdida de Génova cf. PACINI, A., La Genova di Andrea Doria nell' impero di Carlo V, Florencia, 1999, p. 266 e sgg.

10 La respuesta de Carlos V fue: «Sobre este primer capítulo plaze a su magestad que así se haga, en buena, ampla y segura forma, con la reservación de la auctoridad imperial». El contrato está publicado en DE CADENAS Y VINCENT, V.: El protectorado de Carlos V en Génova. La 'condotta' de Andrea Doria, Madrid, 1977, pp. 85-88, y en De LAIGLESIA F.: Estudios históricos (1515-1555), I, Madrid, 1918, pp. 148-151.

Hispania, LXV/1, núm. 219 (2005) 21-44 
sivos Habsburgo de España, y que se sustentaba en un trueque de naturaleza eminentemente política: fidelidad a cambio de protección. Esto es, fidelidad de Génova a la alianza imperial en su conflicto con Francia; protección y salvaguardia de la libertad ciudadana por parte de Carlos V. El compromiso de fidelidad de Génova se manifestó principalmente en su decisión de poner en manos del Emperador los servicios de dos sectores claves de su economía: el armamento marítimo y el crédito ${ }^{11}$.

Alianza hispano-imperial sobre el tablero europeo y forma de gobierno republicana en política interna se convirtieron desde ese momento en dos caras de la misma moneda. Se trataba de dos elementos de identidad en los que se sentía representada la clase dirigente ciudadana. De modo paralelo, se fue afirmando de manera definitiva en la elite de gobierno española la conciencia de la importancia del aporte genovés.

En uno de los momentos cruciales para el futuro de la Monarquía Católica en el área mediterránea, cuando después de la paz de Crépy de 1544 Carlos V se encontró frente a la famosa 'alternativa' de si ceder a Carlos de Orléans la Lombardía o los Países Bajos, Génova entró con todo derecho en el debate que entonces se desarrollón ${ }^{12}$. El cardenal de Toledo Juan Pardo de Tavera sostuvo que la cesión de Milán no debería comportar riesgos para los dominios italianos pero tampoco para Génova a pesar de "que se dize que teniendo el rey de Francia a Milán la señorearía luego». En su opinión, la república se defendería, permaneciendo fiel al Emperador, porque era su interés en vista de los beneficios que la protección cesárea le garantizaba ${ }^{13}$. A este simple auspicio, el duque de Alba opu-

1 Para las relaciones financieras entre los genoveses y la monarquía baste recordar algunos textos clásicos como Braudel, F.: La Méditerranée et le Monde méditerranéen à l'époque de Philippe II, París, 1966, Carande, R.: Carlos $V$ y sus banqueros, Madrid, 1965-67, RuIz MarTín, F.: Lettres marchandes échangées entre Florence et Medina del Campo, París, 1965 (la introducción actualmente ha sido reeditada en Pequeño capitalismo, gran capitalismo. Simón Ruiz y sus negocios en Florencia, Barcelona, 1990), IDEM: «Las finanzas españolas durante el reinado de Felipe II», en Cuadernos de Historia, anexos de la revista Hipania, (Madrid) 2 (1968) pp. 114-173, UlloA, M.: La bacienda real de Castilla en el reinado de Felipe II, Madrid, 1986, ( $3^{\star}$ edición revisada), DORIA, G.: «Un quadriennio critico: 1575-1578. Contrasti e nuovi orientamenti nella società genovese nel quadro della crisi finanziaria spagnola", en Fatti e idee di storia economica nei secoli XII-XX. Studi dedicati a Franco Borlandi, Bolonia, 1977, pp. 377-394, IDEM: "Conoscenza del mercato e sistema informativo: il know-how dei mercanti-finanzieri genovesi nei secoli XVI e XVII", en La repubblica internazionale del denaro cit., pp. 57-123. (ahora ambos en IDEM: Nobiltà e investimenti a Genova in Età moderna, Génova, 1995, respectivamente pP. 157-174 y 91-155).

12 Cf. ChabOD, F.: "Milano o i Paesi Bassi? Le discussioni in Spagna sulla "alternativa" del 1544", en Carlos V (1500-1558) Homenaje de la Universitad de Granada, Granada, 1958, pp. 331372, (publicado ulteriormente con modificaciones en Rivista storica italiana, (Turín) LXX (1958) pp. 508-552, y en CHABOD, F.: Carlo $V$ e il suo impero, Turín, 1985, pp. 185-224), IDEM: Lo Stato e la vita religiosa a Milano nellepoca di Carlo $V$, Turín, 1971 , pp. 59 y sgg., IDEM: Storia di Milano nellepoca di Carlo $V$, Turín, 1961, pp. 87 y sgg.

13 Carta del príncipe Felipe a Carlos V del 14 de diciembre de 1544, AGS, Estado 64, ff. 8085, publicada, pero traducida en italiano, en CHABOD, F.: Carlo V e il suo impero cit., pp. 151-159.

Hispania, LXV/1, núm. 219 (2005) 21-44 
so sólidos argumentos: conservar el estado de Milán era imprescindible para defender no sólo Nápoles y Sicilia, sino también los mismos reinos españoles, «porque con tenerle se puede sostener Génova». Por el contrario, renunciar a Lombardía significaba perder Génova y, en este caso, España no tendría un puerto «desde Rosas a Gaeta» para socorrer la Italia meridional. Según Alba, la verdadera clave de la alternativa de 1544 consistía en el dominio del Mediterráneo, del que el eje Milán-Génova era el epicentro; en comparación, los Países Bajos eran «un lago muerto, de donde non se puede pretender más adelante» ${ }^{14}$.

Pocos años después, el mismo Carlos $\mathrm{V}$ se pronunció con estas palabras en la famosa instrucción a su hijo del 18 de enero de 1548 (el llamado "testamento político»): «De Génova [...] debréis de tener cuidado quella esté en vuestra devoción por lo que toca e ymporta a la seguridad de toda Ytalia y a los reynos y estados de Nápoles, Secilia y Milán, y no solamente para esto más aun para los otros reynos de España, yslas de Cerdeña, Mallorca y Minorca» ${ }^{15}$. El emperador hablaba a la luz de recientes y dramáticos acontecimientos. Un año antes, en enero de 1547 , la alianza española y la forma de gobierno republicana se habían tambaleado peligrosamente en Génova a causa de una conjura antidoriana urdida por el conde Gian Luigi Fieschi y destinada a conducir a la ciudad a la órbita francesa. En los meses siguientes algunos de los más influyentes ministros de Carlos $\mathrm{V}$, y en especial el gobernador de Milán, Ferrante Gonzaga, abogaron con énfasis para que en Génova se construyera una fortaleza y se introdujera una guarnición bajo control imperial. No obstante, tuvieron que rendirse a la tenaz oposición de Andrea Doria que ofreció, como contrapartida y a cambio de la estabilidad de la república y de una alianza segura con los Habsburgo, una reforma de las modalidades de elección de los consejos ciudadanos y de las magistraturas más importantes conocida con el nombre de "Garibetto» ${ }^{16}$.

Un significativo testimonio en la consolidación de un posicionamiento español favorable a la salvaguardia de la libertad de Génova y de su forma de gobierno republicana la encontramos con posterioridad a la muerte de Andrea Doria. Una vez desaparecido el viejo almirante, que había sido durante más de treinta años el aval tanto de la fidelidad de Génova a los Habsburgo como de los equilibrios políticos internos entre las fuerzas políticas ciudadanas, se había difundido una gran preocupación por el futuro de la ciudad. A finales de 1558 Gian Andrea Doria, sobrino de Andrea y su futuro heredero, fue por encargo de su tío a la corte de Felipe II en Bruselas. Allí hizo presentes los preocupantes «indicios [...] de altera-

14 Minuta del verbal del Consejo de Estado de noviembre del 1544, AGS, Estado 67, ff. 1316, publicada en CHABOD, F.: Carlo V e il suo impero cit., pp. 218-224.

15 En Papiers d'état du cardinal de Granvelle, C. Weiss (ed.), París, 1842, III, pp. 267-318, espec. pp. 283-284 (pero también en DE LAIGLESIA, F.: Estudios históricos cit., I, pp. 93-120). Cf. BRANDI, K.: Carlo V, Turín, 1961, pp. 577-581; CHABOD, F.: Carlo V e il suo impero cit., pp. 142147; y De CADENAS Y VINCENT, V.: La berencia imperial de Carlos V en Italia: el Milanesado, Madrid, 1978 , pp. 419-422.

16 Cf. PACINI, A.: La Genova di Andrea Doria cit., pp. 593 y sgg. 
ción y novedades» que se estaban manifestando en la ciudad ligur, y pidió que se emitieran órdenes para consentir, en caso de necesidad, una intervención de las tropas españolas asentadas en Lombardía. El soberano no dio su aprobación a este plan considerando «los daños, inconvenientes y difficultades que se seguirían de ponello en execución». Como ya había hecho en el pasado, no consideró oportuno recurrir a la fuerza con los inquietos genoveses, «sino conservarlos en su libertad a nuestra devoción con buenas obras» ${ }^{17}$.

\section{LA QUIETUD ANTES DE LA TEMPESTAD}

Superado el escollo de la primera bancarrota española de 1557, y no habiendo sufrido la ciudad conmociones por la muerte de Andrea Doria (el almirante falleció en noviembre de 1560), la simbiosis entre la república de San Jorge y la monarquía española pareció asumir de nuevo los caracteres de una relación recíprocamente conveniente y, de hecho, inseparable. Así lo testimonia un memorial sobre el funcionamiento de la embajada española en Génova, que se puede fechar en el otoño-invierno de 1571-72, y que, tal vez, podamos atribuir a la mano del secretario de embajada (y cónsul de la nación española en Génova) Francisco de Ugarte ${ }^{18}$. El memorial proporciona un interesante cuadro de las relaciones hispano-genovesas que abarca también aspectos cotidianos menos conocidos pero no por ello menos importantes.

Según Ugarte, el embajador español en Génova era una figura especial, distinta del típico representante del rey en un estado extranjero. Podía servir a la Monarquía de muchas formas, y ello «por lo poco que tiene que hazer en los negocios de estado", dado que la república se había puesto «de todo punto en manos» de Felipe II; esto es, se había entregado a su servicio «sin pasarle por la yma-

17 Carta de Felipe II al embajador Gómez Suárez de Figuera del 13 de febrero de 1559, AGS, Estado 1388, f. 97, pero cf. también los ff. 96 y 98.

18 El documento, no fechado ni firmado, tiene como título «Sobre el embajador de Génova», AGS, Patronato Real, legajo 45, doc. 83. La datación es posible por una alusión a la enfermedad del embajador Antonio de Mendoza surgida «este verano». Mendoza tuvo graves crisis nerviosas desde finales de abril de 1571 que no le permitieron seguir con sus funciones y obligaron a Felipe II a sustituirlo por Sancho de Padilla (cf. AGS, Estado 1401, ff. 24-27, 31, 84 [...], como en Magdaleno, R.: Papeles de Estado Génova, Valladolid, 1973, p. 104). Padilla no puede ser el autor del memorial visto que se habla de él en tercera persona. El secretario de embajada de Mendoza, Miguel de Oviedo, por cuanto pródigo de consejos sobre la reorganización de la sede diplomática genovesa en las cartas a Felipe II, estuvo encargado poco tiempo para poder redactar un documento tan detallado. Además, del contenido del memorial se deduce que fue escrito en Madrid (o al menos en España), y sabemos que Francisco de Ugarte, secretario durante largos años del embajador Gómez Suárez de Figueroa y que, por lo tanto, era capaz de dar sugerencias circunstanciales acerca del funcionamiento de la embajada, fue llamado a la Corte en 1571 para arreglar las cuentas de Figueroa, muerto en 1569 (cf. las cartas de Ugarte a Felipe II del 10 de febrero, 31 de marzo y 29 de abril de 1571, AGS, Estado 1401, ff. 28-31).

Hispania, LXV/1, núm. 219 (2005) 21-44 
ginación dexallo siempre de hazer en todos tiempos y occasiones». Tal situación derivaba de las decisiones estratégicas de la clase dirigente ciudadana que tenía como objetivo conservar la propia libertad bajo la protección de un «príncipe poderoso» dispuesto a defender la república de las agresiones externas. Otra característica de este tipo de príncipe protector era que debía poseer «grandes y ricos estados», donde los genoveses pudieran "ganar de comer con sus yndustrias», dado que la esterilidad del suelo ligur no les consentía cultivar sueños de autarquía. Se trataba del retrato inconfundible de Felipe II o, al menos, ningún otro monarca de la cristiandad se le parecía tanto. De él los genoveses habían experimentado «bondad, grandeza y riqueza de estados» por lo que se habían inclinado por una elección que parecía definitiva. De esta situación derivaba la confianza absoluta de la Señoría en el embajador español, al que se informaba de los «negocios de estado" y al que se consultaba sobre cualquier cuestión importante «como si fuesse ciudadano». En resumen, el interés del rey de España y de la república eran una misma cosa. La simbiosis era perfecta y no había por qué temer contactos o acuerdos secretos con otros príncipes.

Ahora bien, las oportunidades que ofrecía el sistema imperial español constituían también un importante vínculo. La situación descrita anteriormente carecía de alternativas porque la ciudad podía sobrevivir sólo con «las vituallas que vienen de los estados de vuestra magestad» (sobre todo de Sicilia); los comercios de la "gente común", en especial los concernientes a materias primas como seda y lana, estaban centrados en esas mismas áreas. Por último, había un tercer elemento fundamental: el hecho de que muchos ciudadanos, si bien bajo el nombre de pocos, tenían sumas ingentes empeñadas en los préstamos establecidos con Felipe II. Esto significaba «que sin general ruina de todos no se pueden apartar de su servicio", a menos que no se redujeran a la desesperación debido a unos hipotéticos malos tratos que el soberano no tenía ningún interés en poner en marcha.

Ugarte no se explayó sobre la importancia de conservar la alianza de la república «pues es cosa tan sabida», y pasó directamente a describir el ambiente en el que el embajador debía ejecutar su encargo. La ciudad, dirigida por un único orden nobiliario creado con la reforma de 1528 , estaba en realidad dividida en «tres estados»: nobles viejos, descendientes de linajes nobles desde antes de 1528; nobles nuevos, provenientes de familias que antes de 1528 habían participado en la administración de la república en cuanto pertenecientes al pueblo, y que en esa fecha habían entrado en el nuevo orden de los cives nobiles; populares, que estaban fuera del grupo dirigente ${ }^{19}$. Desde un punto de vista numérico, los Viejos eran el componente minoritario de la clase de gobierno, de la que los Nuevos representaban a la mayoría; los populares, excluidos del poder pero que aspiraban a acceder a él, eran más numerosos «que estas otras dos parcialidades juntas» ${ }^{20}$. Entre los

19 Cf. PACINI, A.: I presupposti politici cit., pp. 347 e sgg.

20 Cf. PACINI, A.: La Genova di Andrea Doria cit., pp. 511 y sgg. 
exponentes de los tres órdenes existían grandes discrepancias. Viejos y Nuevos se odiaban hasta tal punto que no entraban en contacto si no era por motivos de negocios; el pueblo odiaba a todos los nobles, pero, sobre todo, a los Nuevos porque sin ningún título o cualidad especial y por el mero hecho de haber sido agregados a la nobleza en 1528, ejercitaban el poder y disfrutaban de la mitad de los oficios. El riesgo de que explotaran conflictos sociales se convertía en una realidad más que plausible. Además, en ese caso, habrían sido muy difíciles de gestionar porque no había ningún personaje dotado de la suficiente autoridad y prestigio como para desempeñar el cargo de moderador e intermediario entre las partes. Función que había desempeñado hasta el momento Andrea Doria y, después de su muerte, el banquero Adamo Centurione y el coronel Agostino Spinola, si bien durante breve tiempo. El joven Gian Andrea Doria estaba todo el año ausente para servir a Felipe II con las galeras y no podía representar el papel que antes desempeñó su tío.

Todo esto imponía una doble cautela tanto en la elección del embajador como en sus líneas de actuación. Primero, era imprescindible que fuera una "persona bien nacida», porque esto le confería reputación y crédito, sin olvidar que los genoveses eran extremadamente "pláticos de España», y capaces de interpretar con precisión jerarquías sociales y de prestigio. El embajador elegido debía tener como objetivo hacerse querer por todos «sin ser parcial a ningún estado»; honrar a cada uno según sus cualidades, pecando mejor de familiaridad y confianza que de gravedad; favorecer a los nobles en sus negocios con la Corte escribiendo cartas de recomendación al rey y a sus ministros; hablar siempre haciendo èntender que él deseaba la prosperidad de la república al igual que la de los ciudadanos, y que era interés e intención de la monarquía mantener a la ciudad rica e independiente. En resumen, el mensaje que había que transmitir era que una Génova república libre convenía más a Felipe II "que tenella domenada con un castillo que en ella tubiese». Si procedía de esta forma el embajador conservaría a la elite del gobierno obligada, contenta y preparada para cualquier servicio. Aún así, tenía que ayudar también a los exponentes del pueblo; así «le tendrán todos por padre», y podría ser intermediario y conciliador en el caso de que estallara una revuelta. Un estallido repentino era lo único de lo que se podía tener miedo, «porque de pensado no se puede tomar en aquella república resolución, por las razones dichas, que sea en deservicio de vuestra magestad», todavía más después del reciente asentamiento de tropas españolas en el castillo de Finale, de por sí suficientes para controlar a los genoveses ${ }^{21}$.

En el memorial se examinaban además las atribuciones concretas del embajador. Génova era un importante centro de tránsito de la correspondencia entre los ministros españoles y la Corte y Ugarte propuso algunos cambios relevantes

21 Sobre los acontecimientos de Finale cf. Edelmayer, F.: Maximilian II., Philipp II. und Reichsitalien. Die Auseinandersetzungen um das Reichslehen Finale in Ligurien, Stuttgart, 1988.

Hispania, LXV/1, núm. 219 (2005) 21-44 
en el sistema vigente. La república, hasta entonces lugar de paso de los correos para Italia, tenía que convertirse en el centro principal de distribución de los despachos. Sería el embajador el que clasificaría las cartas, recurriendo según lo requiriese la urgencia del caso a correos especiales u ordinarios que cada semana debían partir hacia las distintas capitales italianas. Este tipo de sistema comportaría numerosas ventajas derivadas del hecho de mantener secreto el destino final de los pliegos. Se eliminaría también la mala costumbre por la que los correos, a pesar de la prohibición vigente, llevasen también cartas privadas y se lograría frenar el gran hablar (y escribir) «de los estrangeros que están en la corte», que "con el cuydado que tienen de saver lo que se trata en el mundo", conociendo el destino de los correos preavisaban de las órdenes que venían de Madrid. Era una jugada útil para controlar, al menos en parte, el flujo de las informaciones y divulgar sólo «lo que allá [en la corte] quisieren que se sepa». Y, además, se ahorraría dinero: separando los tramos entre Madrid y Roma, Nápoles y Palermo el costo de los correos disminuiría entre el 7 y el 12,5\% o aún más si el correo de Milán se encargaba de transportar también los despachos de las otras capitales italianas.

Uno de los deberes fundamentales del embajador era proveer de vituallas y municiones a la flota española y a la infantería embarcada. También en este aspecto las cosas tenían que mejorar. Hasta entonces las adquisiciones se habían hecho en el último momento, cuando la necesidad apremiaba. Las imponentes cantidades movilizadas comportaban siempre un alza de los precios, con su inevitable daño económico, y eran un reflejo elocuente de los movimientos de tropas que la monarquía estaba realizando con el consiguiente daño políticoestratégico. Además, la necesidad urgente inducía a adquirir las mercancías en la ciudad, después de que los mercaderes hubieran pagado las gabelas de entrada, por lo que no se aprovechaba la exención que la república reconocía a Felipe II. Los «excessivos derechos» eran un gasto significativo: el 33\% del valor para el vino y el vinagre, el 25 para la carne fresca, el 15 para el tocino y el queso salado, el 12 para las sardinas y las anchoas; el 10 para habas, garbanzos, arroz y «bizcocho». Las armas, la pólvora, los metales, los instrumentos para las galeras y los tejidos de baja calidad para la tripulación estaban gravados entre el 10 y el $12 \%$. Por lo tanto, comprando fuera de Génova se eliminaría el costo de las gabelas. Por otra parte, habida cuenta de la regularidad que caracterizaba la movilidad de las fuerzas terrestres y navales españolas en Liguria, se podrían acumular importantes reservas adquiriendo las mercancías en aquellos momentos en los que su precio fuese más bajo lo que limitaría las subidas determinadas por el exceso de demanda. Se dejarían así de padecer las maniobras especuladoras ejercidas por los mercaderes que se abastecían incluso en los reinos de la monarquía ${ }^{22}$. Las reservas tenían que gestionarse y renovarse con cuidado, lo que permitiría obtener además un cierto beneficio económico.

22 El memorial contiene una detallada lista de las áreas de donde provenían y en las que era más conveniente adquirir las distintas mercancías: para las vituallas, los reinos de Sicilia (trigo y 
Para que todo esto fuera posible, el embajador debía tener un cierto grado de autonomía financiera, y la embajada contar con personal experto y de confianza (en especial «un tenedor de bastimentos platico de municiones y vituallas») capaz de dar consejos sobre dónde y cuándo comprar, de controlar la calidad de las mercancías, y de gestionar el flujo de entrada y de salida de los almacenes. Como alternativa, Ugarte sugería subastar en bloque las provisiones a mercaderes que ofrecieran la garantía de un ahorro del $10 \%$ sobre el precio habitual de las mercancías en Génova en el momento del abastecimiento.

Otro sector fundamental en el que el embajador podía aportar su ayuda era el del crédito. Ugarte distinguía tres tipos distintos de operaciones: las de gastos ordinarios, hasta 3000 ó 4.000 ducados; las «de mayor cantidad», más de 15.000 ducados y hasta 50.000; y, por último, «las partidas gruessas» de 200.000 a 300.000 ducados. Para el primer tipo no era necesario una orden específica del rey ni una negociación en su nombre. El embajador recurría a sus amigos y confidentes acumulando el débito hasta dicha cifra, emitía después una letra de cambio a Madrid para legitimar el interés, y reembolsaba lo que debía con el dinero que periódicamente llegaba con las galeras. Los contratos del segundo tipo (de 15.000 a 50.000 ducados) eran más difíciles de efectuar a principios de los años 70 que lo habían sido en el pasado. Tomar a cambio sobre las ferias de España (es decir, con reembolso efectivo en tierra ibérica) era muy caro, tanto que los mismos mercaderes lo evitaban. El interés era tal «que los que lo dan tienen verguença de llevarlo, y los que lo toman no pueden pagar». La «carestía de dinero»en las relaciones con las ferias de Castilla no se debía a la caída del crédito de los ministros españoles en Italia, «que jamás le tuvieron mayor que agora», ni a la falta de dinero de los mercaderes-banqueros genoveses «que están muy ricos y con más necessidad que nunca de tratar con vuestra magestad», sino a los retrasos de los pagos en España de seis, nueve o incluso doce meses en los últimos años. Se podía arreglar esta situación «reduciendo las ferias a lo que solían", es decir, volviendo a pagar con puntualidad, o estableciendo un interés fijo del $10 \%$ anual para los retrasos con un empeño formal por parte de Felipe II. Más fácil (y conveniente) era cambiar en las ferias de Italia, entre las que estaban también las de Besançon, gestionadas directamente por los genoveses, con reembolso en efectivo del dinero que llegaba de España.

Los grandes asientos (200.000-300.000 ducados) se tenían que hacer en Madrid. Se trataba de un cambio fundamental que se había producido con la sucesión al trono de Felipe II. En la corte, el rey era capaz de ofrecer a los mercaderes «muchas maneras de grangerías que para ellos son de ymportancia y para vuestra

\footnotetext{
legumbres), de Nápoles (legumbres) y de Cerdeña (queso), el ducado de Milán (arroz), Cataluña (pescado salado), Mallorca (legumbres), Liguria (tocino, aceite y vino), Piamonte (tocino). En caso de malas cosechas de aceite y vino en Liguria se podía recurrir a la Provenza; para los tejidos y materias vegetales necesarias para las galeras y la tripulación, Liguria, Provenza y Piamonte; para las armas, las municiones y los metales en general, el ducado de Milán; para el salitre y la pólvora también el reino de Nápoles.
}

Hispania, LXV/1, núm. 219 (2005) 21-44 
magestad de poco daño", sobre todo con maniobras concernientes a los títulos del débito público consolidado. Podía dar licencias para la adquisición de «juros de por vida» y para su transmisión hereditaria, aumentar su rendimiento, concederlos nuevos o darlos en préstamo; podía jugar con el tipo de «consignación», más o menos reputada, para la extinción del débito. Existían, en suma, muchas formas para tentar a los mercaderes, que «están muy ricos y habraçarán de muy buena gana servir a vuestra magestad augmentando su hazienda».

Para tener dinero en abundancia y a bajo precio existían otros métodos. Uno de los más adecuados era que Felipe II obtuviera del Papa la eliminación de la censura eclesiástica concerniente a los cambios y a la usura para todas aquellas personas implicadas en los préstamos a la monarquía, ya fuesen las figuras clave de los mercaderes-banqueros como la de quienes les confiaban su dinero. La defensa de la cristiandad y de la autoridad de la sede apostólica en tiempos de lucha contra los turcos y los herejes era un argumento que podía ser bien recibido en Roma. Una vez desaparecido este obstáculo jurídico y de conciencia, en Génova muchas "personas de caudal» prestarían fácilmente al rey un millón de ducados en caso de necesidad. Con respecto a los tiempos de Carlos V la riqueza había crecido mucho y no habían disminuido los servidores de España, convencidos de que «la conservación de su reppública consiste en estar en Italia poderosas las armas de vuestra magestad».

Ugarte parecía despreocupado, sin razón, ante el crecimiento de la deuda pública castellana mientras que sí suscitaba su alarma otro de los mecanismos con los que la monarquía había logrado atraerse a la elite financiera genovesa. Aún justificándose por el hecho de moverse en un terreno que poco tenía que ver con la embajada de Génova, recordó los inconvenientes derivados del «vender estados en el reyno de Nápoles", incluso cuando se introducían como concesión en las cláusulas de retroventa destinadas a ser ineficaces. El sur de Italia era una especie de depósito feudal al que Carlos $\mathrm{V}$ y Felipe II habían recurrido muchas veces sin considerar suficientemente que los feudos eran vendidos para siempre, y concedidos a personas, los genoveses, que «siendo hijos de reppública [...] no se tienen por vasallos suyos", y, por lo tanto, eran de dudosa fiabilidad. Los adquirían a precios bajos, aprovechándose de las dificultades financieras de la monarquía, y podían vender o registrar a un testaferro sus posesiones sin tener que pedir licencia al rey, y pasar sin ningún riesgo a servir a otro príncipe $^{23}$. El «desempeño» financiero, que desde hacía tiempo Cortes y Parlamentos habían impuesto como uno de los objetivos prioritarios de la monarquía, era evidente que iría «muy a la larga». Primero se debía eliminar el débito a corto plazo y con altas tasas de interés, los asientos, «que hazen mayor daño»;

23 En la amplia literatura sobre los genoveses en el reino de Nápoles, cf. los recientes trabajos de Musi, A.: Mercanti genovesi nel regno di Napoli, Nápoles, 1996; BRANCACCIO, G.: «Nazione genovese». Consoli e colonia nella Napoli moderna, Nápoles, 2001, y específicamente sobre el problema de los feudos Cernigliaro, A.: Sovranità e feudo nel regno di Napoli 1505-1557, Nápoles, 1983, y DeLILLE, G.: Famiglia e proprietà nel regno di Napoli: XV-XIX secolo, Turín, 1988. 
después los juros, que en el reino de Nápoles costaban el 10\% de interés, «y lo ultimo ha de venir a ser los tales estados», que podían considerarse definitivamente perdidos ${ }^{24}$.

\section{Pequeñas intrigas: los procesos de toma de decisiones en la COR- TE DE FELIPE II SOBRE LA REVUELTA GENOVESA DE 1575}

El análisis de la situación política interna realizado por Francisco de Ugarte aparece claro y rico de sugerencias en todo aquello relativo a la "estática» (es decir, a los elementos estructurales) de las relaciones hispano-genovesas, pero resulta ser insuficiente en otros muchos aspectos, sobre todo en lo relativo a las previsiones de futuro. A los tres años, en 1575, estalló en Génova una revuelta popular de características muy distintas a la de las hipótesis que había realizado el secretario de la embajada. En primer lugar no se trató de un "casso repentino" sino de la maduración progresiva de tensiones que a partir de 1573 se hicieron cada vez más graves, concerniendo primero, en un crescendo de intensidad, a los procedimientos electorales y después al orden constitucional de la república. Las líneas de ruptura en la sociedad genovesa y las fuerzas en juego (nobles viejos, nobles nuevos y pueblo) fueron las indicadas por Ugarte, pero no su actitud ni su programa político. En la raíz de la revuelta encontramos a los Nuevos y al pueblo aliados contra los Viejos, los cuales constituían el mayor referente por la relación privilegiada que mantenían con España. A este grupo político pertenecían los principales mercaderes-banqueros, que eran los recaudadores de crédito para la monarquía, y los armadores de galeras, que servían en la flota de Felipe II.

El conflicto entre Viejos y Nuevos sobre los procedimientos electorales durante la revuelta ha quedado bien ilustrado en el libro de Rodofo Savelli ${ }^{25}$. La alianza Nuevos-pueblo se alcanzó sobre la base de un acuerdo que preveía una pluralidad de objetivos capaces de satisfacer exigencias y reivindicaciones de diverso tipo. Los Nuevos querían la abolición del Garibetto (la ley promulgada en 1547 que, introduciendo la nómina por votación de las magistraturas de vértice, garantizaba a los Viejos la mitad de los puestos en la Señoría) y la aplicación integral de las Reformationes Novae de 1528 (que preveían en cambio la designación por sorteo); el así llamado pueblo grasso, gravemente penalizado por el bloqueo de las inscripciones a la nobleza, pedía el acceso a los rangos de la

\footnotetext{
24 Por lo que concierne al tema del «desempeño» en las Cortes castellanas cf. FORTEA PÈreZ, J. I.: Monarquía y Cortes en la corona de Castilla. Las ciudades ante la política fiscal de Felipe II, Cortes de Castilla y León, 1990.

25 Sobre la revuelta de 1575 cf. SAVELLI, R.: La repubblica oligarchica. Legislazione, istituzioni e ceti a Genova nel Cinquecento, Milán, 1981, y PACINI, A.: "El "padre" y la "república perfecta": Génova y la Monarquía española en 1575", en Bravo, J. (ed.): Espacios de Poder: Cortes, Ciudades y Villas (s. XVIXVIII), Madrid, 2002, II, pp. 119-132.
}

Hispania, LXV/1, núm. 219 (2005) 21-44 
clase de gobierno; para el pueblo minuto y la plebe urbana la disminución de la imposición indirecta y el aumento del nivel de los salarios representaban eficaces factores de movilización.

Aun siendo tan distintos, pueblo grasso y pueblo minuto compartían además la sensibilidad por algunos temas propagandísticos usados por los Nuevos contra los Viejos: la condena de las excesivas riquezas y del gran poder de pocos así como de la esterilidad (y dudosa conformidad con la moral cristiana) de los cambios y de los negocios financieros. Criticaban también la infiltración de costumbres y estilos de vida aristocrático-feudales contrarios a aquellos ciudadanos-republicanos y la sumisión a España de una república debilitada de modo intencionado para someterla mejor al dominio de una minoría. Por el contrario exaltaban una tradición mercantil y marinera fecunda y vivificadora de la sociedad urbana, propia de la forma de gobierno republicana, ética y moralmente digna de una comunidad cristiana. Todas estas argumentaciones encontraban un fuerte eco en los ambientes populares que podían utilizarlos de forma más o menos instrumental o proceder a una reelaboración autónoma de los mismos ${ }^{26}$.

Después de algunas señales iniciales y de un enésimo y fallido intento de mediación por parte del embajador español, Juan de Idiáquez, los tumultos comenzaron el 15 de marzo. Bajo la presión de la plebe en armas, la Señoría cedió rápidamente a todas las peticiones que provenían del frente unitario entre Nuevos y pueblo: el odiado Garibetto se abolió; se prometieron trescientas inscripciones a la nobleza; se procedió al aumento del salario de los tejedores y se redujo la gabela del vino. La revuelta se contuvo, pero el pueblo no depuso las armas. Enseguida comenzó el éxodo de los Viejos que abandonaron la ciudad para dirigirse a sus mansiones y encontrar más tarde refugio fuera del dominio de la república. En su condición de exiliados, eligieron Finale para reorganizar sus filas y establecer el centro de mando. Al pasar el plazo establecido por la ley, los Viejos ausentes de las magistraturas fueron sustituidos por exponentes del partido contrario. Para entonces el poder estaba plenamente en manos de los Nuevos.

Pero una vez en marcha, la revuelta superó su dimensión ciudadana. Muchos veían en ella una amenaza a la paz en el mundo católico. Las Cortes de media Europa se prepararon ante la posibilidad de que Felipe II se adueñara de Génova. Un fortalecimiento de la posición española en Italia contaba con una oposición generalizada: el rey de Francia, tradicional antagonista de los Habsburgo; los príncipes italianos, respetuosos por necesidad e interés ante la potencia hegemónica pero aliados poco fiables, en cuanto que, por un lado, temían las miras territoriales de Felipe II y, por otro, esperaban las oportunidades ofrecidas por un cambio en el equilibrio de poder en la península; el emperador

26 Cf. SAvelli, R.: «Tra Machiavelli e S. Giorgio. Cultura giuspolitica e dibattito istituzionale a Genova nel Cinque-Seicento", en DE MADDAlenA, A. e KellenbenZ, H. (eds.): Finanze e ragion di Stato in Italia e in Germania nella prima Età moderna, Bolonia, 1984, pp. 249-321.

Hispania, LXV/1, núm. 219 (2005) 21-44 
Maximiliano de Habsburgo que ostentaba sobre Génova, en calidad de ciudad imperial, la alta soberanía no parecía dispuesto a ver aún más limitado su papel en Italia septentrional en beneficio de su primo; y, por último, el pontífice, Gregorio XIII, decidido a reafirmar la propia función de mediador entre los príncipes católicos, en principio unido con ellos en la lucha antiprotestante y antiturca pero al mismo tiempo interesado en defender los intereses de la Iglesia en cuanto estado territorial y potencia supranacional.

En los dos años anteriores España había seguido con atención el desarrollo de la situación genovesa. La acción de Felipe II se había articulado en dos planos. En principio, y a través de sus embajadores Sancho de Padilla y Juan de Idiáquez, intentó una mediación entre. Viejos y Nuevos en vistas a obtener un acuerdo que eliminase definitivamente los motivos de la contienda. En segundo lugar, tomó en seria consideración la eventualidad de una intervención militar de las tropas alojadas en Lombardía y de la flota en el caso de que las tensiones políticas degeneraran en un conflicto abierto. El gobernador de Milán, marqués de Ayamonte, tenía la orden explícita de bajar a Génova previa petición de Idiáquez.

Por cuanto preventiva y programada, la opción militar se reveló impracticable en el momento en que estallaron los desórdenes. Eventuales movimientos de tropas en Lombardía habrían agravado la situación. La revuelta no tenía todavía una evidente connotación antiespañola, y con el uso de las armas se arriesgaba a que la república quedara fuera del bloque habsbúrgico ${ }^{27}$.

La repentina medida emprendida por Gregorio XIII, que a primeros de abril envió a Génova un nuncio, el hábil y experto cardenal Giovanni Morone, hizo definitivamente impracticable la vía de la intervención armada. Algunas semanas más tarde llegaron también dos comisarios imperiales. Felipe II tenía en Génova a Juan de Idiáquez pero, para crear un contrapeso al prestigioso cardenal Morone, que se mostró pronto sospechoso a los ojos de los españoles, nombró como su representante al duque de Gandía que, debido a varios contratiempos, tardó en llegar hasta mediados de agosto. Para entonces ya se había constituido una mesa para negociar la solución de lo que ya era un grave problema internacional y a la que también le hubiera gustado enviar un representante al rey de Francia que, al final, no lo logró.

Proseguir por la vía de la mediación parecía ser en esos momentos la única posibilidad. Restablecer «paz, quietud y sosiego» en la república se convirtió, por ende, en la orden oficial de la diplomacia española en los meses sucesivos. Los Viejos, sin embargo, habían puesto en marcha una estrategia alternativa: si Felipe II tenía las manos atadas, ellos podían recurrir de modo autónomo a las armas. Eran propietarios de una de las mayores flotas del Mediterráneo occidental y tenían recursos financieros suficientes para actuar por si solos. Fue entonces cuando pidieron al soberano, a cuyo servicio militaban las galeras, la obtención

27 Cf. las cartas de Idiáquez a Felipe II del 12 de febrero y 18 de marzo de 1575, AGS, Estado 1407 , ff. 5 y 16.

Hispania, LXV/1, núm. 219 (2005) 21-44 
de una licencia para declarar la guerra a la república, un paso de una gravedad inusitada. Por lo tanto, para entender el posterior desarrollo de los acontecimientos, además de a Génova hay que mirar hacia Madrid y hacia la Corte de Felipe II, teatro de una intrigante sucesión de eventos de graves consecuencias. Toda Europa tenía los ojos puestos en la capital del imperio español. Era allí donde deberían adoptarse las decisiones fundamentales que permitirían desatar el complejo nudo genovés del que parecía depender la paz o la guerra en el mundo católico, lo que acarrearía una serie de consecuencias incalculables debido al doble conflicto en los Países Bajos y con el imperio otomano.

El problema consistía en cómo traducir en decisiones operativas el modelo estratégico de la política italiana y mediterránea de la monarquía en el que, como hemos visto, el control de Génova por parte del Rey Católico era una pieza fundamental. En este contexto es esencial tomar en consideración, además de las formulaciones discursivas más o menos estratégicamente significativas de este o aquel exponente de la corte, los mecanismos de toma de decisiones en su cruda y concreta articulación, y el contexto en el que éstos funcionaban.

Como es sabido, la Corte de Madrid estaba en aquel momento atravesando una incierta fase de transición después de la muerte en 1573 del cardenal Espinosa. No existía ya una figura dominante y la cuestión genovesa se convirtió en uno de los terrenos sobre los que se desarrolló en la Corte una lucha por conquistar el favor regio. Otro tema candente, estrechamente unido con los acontecimientos en curso en Génova, era el del «desempeño» financiero de la monarquía, que implicaba la renuncia por parte de Felipe II al tradicional instrumento de los asientos, es decir, a los préstamos a breve término y a un alto tipo de interés en el que los mercaderes-banqueros ligures se habían especializado ${ }^{28}$.

Licencia y desempeño fueron los dos polos sobre los que se articuló la política de Felipe II en estos meses con resultados, como mínimo, desconcertantes. Uno de los efectos de tal desconcierto fue el inicio, a mediados de septiembre, de la guerra privada emprendida por los nobles viejos contra la república mediante el uso de las galeras de su propiedad, que formalmente ya no se encontraban al servicio del rey de España, y con infantería alemana e italiana que había sido licenciada previamente por los ministros de Felipe II y cuya financiación procedía del dinero recogido por los exiliados en Finale. Hasta el momento no se ha logrado aclarar cómo se alcanzó esta solución. La responsabilidad de la guerra ha sido atribuida generalmente a Juan de Austria, comandante de la flota española en el Mediterráneo, que por propia iniciativa habría dado vía libre al comienzo de las operaciones militares. Pero nada se ha dicho sobre cómo fue tomada aquella decisión ni sobre los mecanismos que la determinaron.

A partir de marzo de 1575 llegó a la Corte un raudal de cartas y memoriales con informaciones, juicios y sugerencias concernientes a la situación genove-

28 Cf. Martínez Millán, J. y De Carlos Morales, C. J. (dir.): Felipe II (1527-1598). La configuración de la Monarquía bispana, Junta de Castilla y León, 1998, pp. 133-200.

Hispania, LXV/1, núm. 219 (2005) 21-44 
sa. Todo pasaba por las manos de Felipe II y del secretario Antonio Pérez que decidían acerca del envío del material a los diversos consejos. En primer lugar al Consejo de Estado, dividido por entonces en dos ramas, una numéricamente más consistente y residente en Madrid, y la otra que formaba parte del séquito del soberano en sus frecuentes desplazamientos por los alrededores de la capital castellana ${ }^{29}$. Se producía un rígido control en el flujo de la información: el Consejo de Estado recibía la casi totalidad de las cartas provenientes de Génova y, sobre esta base, discutía lo que se debía de hacer. No ocurría lo mismo con todas aquéllas provenientes de Roma que, vista la implicación directa de Gregorio XIII en las negociaciones para la pacificación de la república a través del cardenal Morone, habrían sido fundamentales. Dichas cartas eran remitidas a Francisco de Garnica en cuanto miembro de la «Junta de presidentes» encargada de las cuestiones financieras, dado que en Roma el embajador, Juan de Zúñiga, estaba tratando una renovación plurianual del drenaje fiscal sobre las entradas eclesiásticas españolas.

Sobre la base de informaciones previamente seleccionadas por otros, la solicitud de licencia realizada por los Viejos fue llevada al Consejo de Estado en abril. Se produjo entonces una dura contraposición de pareceres entre el duque de Alba y el inquisidor general, Gaspar de Quiroga. El duque se declaró a favor de la licencia, subrayando con fuerza que Felipe II debía fiarse tan sólo de los Viejos, sus tradicionales aliados. Su obligación consistía en reintegrarlos en las posiciones que disfrutaban antes de la revuelta, mediante el restablecimiento de la ley del Garibetto, como única alternativa para mantener la alianza genovesa. Quiroga, en cambio, era contrario a cualquier hipótesis que entrañase el uso de la fuerza, en cuanto que habría llevado a la monarquía a un choque con el papado. Defendía por ello las decisiones adoptadas por la república que, a su parecer, era libre de modificar a placer sus propias leyes, por lo que se mostraba propenso a dar crédito a las proclamas de fidelidad a España que los Nuevos incesantemente repetían a través de sus embajadores ${ }^{30}$.

Finalmente fue la línea de Alba la que terminó por imponerse. Felipe II, temeroso de una ruptura abierta con Gregorio XIII y a instancias el duque, puso en pie un complejo artilugio diplomático para prevenir toda posible acusación de haber infringido la paz de la cristiandad. En el centro de dicha maniobra se encontraba Juan de Austria que, a mediados de junio, había enviado a Madrid a su secretario, Juan de Escobedo, para solicitar las órdenes pertinentes $^{31}$. Pero subrayemos algo fundamental: el Consejo de Estado no fue infor-

29 Sobre el funcionamiento del Consejo de Estado a mediados de los años 70 del siglo XVI cf. FERnández CONTI, S.: Los Consejos de Estado y Guerra de la Monarquía bispana en tiempos de Felipe II (1548-1598), Valladolid 1998, pp. 123 y sgg.

30 Cf. PACINI, A.: «El "padre" y la "república perfecta"» cit.

31 Cf. la «Instructión de lo que vos el secretario Juan de Escovedo haveys de hazer en la corte», del 13 de junio de 1575, AGS, Esstado 1067, f. 8.

Hispania, LXV/1, núm. 219 (2005) 21-44 
mado del verdadero contenido de la instrucción que Escobedo recibió el 29 de julio de $1575^{32}$.

En ésta Felipe II apreció el comportamiento de su hermano con respecto a la cuestión genovesa. Don Juan se había comportado de modo adecuado cuando, durante su viaje hacia el sur de Italia en junio y con objeto de evitar posibles incidentes, había optado por no entrar en la ciudad. Lo mismo cabía decir de su decisión de proceder a una serie de consultas entre los principales ministros españoles en Nápoles de las que se habían remitido los informes a la Corte. En Madrid el Consejo de Estado se había reunido varias veces para discutir sobre la solicitud de licencia hecha por los Viejos. Las decisiones tomadas hasta ese momento eran las siguientes: enviar lo antes posible a la ciudad ligur al duque de Gandía, que haría el viaje en compañía del mismo Escobedo, para que hablase a los genoveses «más clara y descubiertamente que hasta aquí»; Gandía llevaría también la propuesta, efectuada por el rey y de forma más resolutiva que en anteriores ocasiones, para que abandonaran enseguida las pasiones y discordias y llegaran de inmediato a un acuerdo. El deber principal del monarca Católico era defender y conservar la «paz pública» en la cristiandad puesto que Felipe II no podía permitir que ésta fuera puesta en peligro. Por ello, exigía que Viejos y Nuevos se entendieran "con mucha brevedad y a satisfación de todos, y de manera que quede muy entera la libertad de aquella república».

En primer lugar se auspiciaba que, a través de una franca discusión entre los dos principales partidos, se volviese a la situación previa al 15 de marzo de 1575 (con la reintegración de los Viejos en el gobierno) dado que los cambios se habían llevado a cabo hasta entonces mediante el uso de la fuerza y contando con el furor de pueblo. Ambos grupos debían renunciar a algunas de sus pretensiones y construir juntos un orden que restituyera a la ciudad «su quietud y sosiego». Esta línea, que no difería mucho de lo realizado en el pasado por Juan de Idiáquez, fue propuesta por Felipe II a pesar de la escasa confianza de una solución que «yo desseo en gran manera [...] aunque esto se tiene por impossible».

El segundo punto de la instrucción tenía por objeto realizar una propuesta para que Nuevos y Viejos aceptasen someter sus controversias al arbitraje del Papa y del rey de España. En este caso Gandía debía procurar la máxima celeridad en las tratativas con Morone pero, sobre todo, actuar de forma que quedase «muy entera la libertad de aquella república y debaxo de mi protectión solamente». Se trataba de una crítica implícita a las operaciones de mediación de Morone visto que, desde España, se reivindicaba un papel supervisor en régimen de exclusividad. Desde el punto de vista de Felipe II, no era justo que teniendo con él tantas obligaciones, y después de tantas pruebas de agradable

32 «Instructión de lo que vos Juan de Escovedo nuestro secretario aveis de dezir al illustrísimo don Juan de Austria, mi muy caro amado hermano, en respuesta de lo que por vuestro medio me embía a comunicar sobre las cosas de Génova», AGS, Estado 1243, f. 51.

Hispania, LXV/1, núm. 219 (2005) 21-44 
cuidado y diligencia los genoveses «ayan de entrar debaxo de otra protectión y amparo". Desde estos postulados se podría tratar con el Papa, el Emperador, el rey de Francia y los potentados italianos. A Gregorio XIII se le animaría a ejercitar una presión conjunta sobre los genoveses para inducirlos al acuerdo; al resto de las potencias se les debería garantizar que el único objetivo de España era la pacificación de la república y la conservación de su libertad.

Se trataba de, mediante el recurso a la vía del diálogo, satisfacer de alguna manera a la opinión pública de las Cortes europeas «para que el mundo entienda que por mi parte se han hecho todas las diligencias possibles para ello». Ahora bien, paralelamente se preparaba una tercera opción: la intervención militar que permitiría poner los intereses de la monarquía en primer plano. Nuevos y pueblo parecían oponerse a cualquier solución de compromiso y nutrían, desde siempre, sentimientos filofranceses. El actual estado de incertidumbre, afirmaba Felipe II, "para mi servicio y bien de mis cosas y estados es el peor que puede tener». Visto que no se podía ya esperar nada bueno de dejar correr el tiempo, parecía necesario llegar a una resolución para que,en el caso de que el camino de los oficios y las tratativas no produjesen nada concreto, «que se venga al del rigor».

Una intervención armada directa de las fuerzas españolas era observada por Felipe II como una posición llena de incógnitas e inconvenientes pues era más que probable que el resto de los estados italianos y Francia acabarían por formar una alianza contra él, dado que lo acusaban de querer adueñarse de la república por la fuerza. Tampoco parecía oportuno intervenir militarmente "por mano de otro» pues el que se adueñara de Génova tendría un arma de extorsión demasiado importante y eficaz. Quedaba, por lo tanto, como única posibilidad actuar con «el medio de los Viejos», concediéndoles la licencia que solicitaban. Se trataba del modo más seguro ya que Felipe II se podía fiar de ellos «por tener tanta parte en ellos como tengo».

La decisión estaba tomada. Se debían dejar quince o veinte días para las tratativas, tiempo que se aprovecharía también para poner a punto la máquina bélica, y después se procedería a autorizar a los Viejos a la guerra. En la puesta en práctica de esta resolución existían aún algunos aspectos políticos delicados que debían abordarse con sutileza. Parecía una temeridad dar comienzo a un conflicto en Italia manteniendo al pontífice al margen pues se corría el riesgo de que éste se convenciera de las acusaciones de los enemigos de España sobre las tendencias expansionista del Rey Católico, y que «se levante de aquí alguna grande polvareda, y el perder a su santidad». Algo que Felipe II no se podía permitir pues, en ese caso, corría el riesgo de perder los beneficios derivados del drenaje fiscal de la iglesia española, sobre el que, justo por entonces, el embajador, Juan de Zúñiga, estaba discutiendo los términos de la renovación con Gregorio XIII.

Tanto el Papa como el Emperador tenían que ser informados pero siguiendo un preciso procedimiento y respetando de modo tajante las modalidades y tiempos que el soberano indicase. Don Juan debería avisar al pontífice con al-

Hispania, LXV/1, núm. 219 (2005) 21-44 
gunas cartas (ya escritas en Madrid y alegadas a la instrucción) que tenían que llegar a su destino antes de la declaración de guerra de los Viejos, pero de modo simultáneo al inicio de las operaciones militares para «que pueda averse començado primero que él lo contradiga». Éste era, afirmó Felipe, «el punto principal deste negocio»: el comunicado del comienzo de las hostilidades tenía que llegar cuando todavía había paz pero de forma que el Papa «no pueda contradezir la execución antes que se aya començado». Se debía ofrecer además la seguridad de que no era el rey de España el que intervenía, sino los nobles Viejos genoveses y que el único objetivo era restaurar la situación de la república anterior a la revuelta.

Después de una serie de largas explicaciones sobre los motivos que justificaban la guerra, la instrucción contenía otro pasaje decisivo por el que se le indicaba al Papa que Felipe II había delegado oficialmente cualquier deliberación en manos de don Juan con el encargo de establecer «lo que más convendrá en este caso, y tome la resolución que más le pareciere convenir, llevando siempre la mira al servicio de nuestro señor y beneficio público». De este modo, el rey delegaba en su hermano cualquier tipo de responsabilidades a los ojos del mundo por el estallido de la guerra dentro de la Europa católica. Se procedía a repetir con insistencia ante el Papa «que viendo mi hermano la cosa en este extremo, y avérselo yo remittido [...] aviéndolo él muy bien considerado como negocio de tanta calidad y que yo le he remittido [...] don Juan «se ha resuelto [...]». La guerra se convertía en «la resolución que el dicho don Juan mi hermano toma en este negocio» y la tercera de las opciones manejadas pasaba a transformarse en una decisión tomada: "presupuesto que la licencia se ha de dar, como está dicho [...]».

Una vez explicados los detalles operativos concernientes a los acuerdos que había que establecer con los nobles Viejos, Felipe II requirió «una cosa [que] importa mucho para el buen successo deste negocion: el secreto. Secreto que había que mantener en un doble plano. Don Juan debía advertir desde el principio a algunos jefes de los Viejos para que iniciaran los preparativos. Eso sí, tendría que ser el menor número posible y se les impondría la máxima discreción. Por otro lado, el secreto más absoluto debía guardarse en la «resolución que yo en esto he tomado» por lo que se exigía que en esto don Juan «no lo comunique a ninguno, ni fíe de nadie».

Éstas fueron las órdenes que el secretario Escobedo llevó a don Juan a mediados de agosto. Mandato que tan sólo conocían otras cuatro personas: Felipe II, Antonio Pérez, el duque de Alba y Juan de Zúñiga, éste último en cuanto encargado de gestionar la delicada comunicación del inicio de la guerra al $\mathrm{Pa}$ pa. El Consejo de Estado no fue informado.

Don Juan ejecutó el plan fielmente. Una vez iniciadas las operaciones militares en la segunda semana de septiembre, los Viejos lograron fácilmente adueñarse de algunos lugares de las Riberas y de la frontera con Lombardía. Tanto en Génova como en Roma la indignación y la consternación se mezcla- 
ron al ver violadas las repetidas promesas de Felipe II de impedir el recurso a las armas. Gregorio XIII llegó a amenazar con una declaración de guerra a España, y se habló incluso de la constitución de una liga itálica contra Felipe II. Fueron pocas semanas de altercados. El encargado de responder a las vehementes protestas del nuncio pontificio en Madrid fue el duque de Alba que, como previsto, descargó cualquier responsabilidad en don Juan ${ }^{33}$.

$\mathrm{Al}$ igual que había ocurrido durante los meses precedentes al inicio de la guerra, el rey y su secretario habían llevado a cabo una obra de filtro con respecto a la documentación relativa a Génova que debía ser enviada al Consejo de Estado, lo que permitía condicionar y dirigir ocultamente sus trabajos. A partir de septiembre no dudaron en recurrir a la censura y a la falsificación de aquellos documentos comprometedores. Felipe II por su puño y letra indicaba las partes de las cartas de Juan de Austria, de Escobedo y de Zúñiga que debían eliminarse o modificarse. Por ejemplo, cuando llegó una carta de don Juan fechada el 6 de febrero de 1576 con algunos parágrafos relativos al «secreto que vuestra magestad mandó guardar en el despacho que truxo Escovedo», Pérez escribió en el margen la siguiente anotación: «Esto no es para consejo, ni lo que sigue desta carta, a lo menos dos capítulos»; y Felipe II confirmó: «Así es que esto no conviene leerlo, ni los dos capítulos que se siguen" ${ }^{34}$. Se omitieron sistemáticamente en las copias de las cartas destinadas al Consejo todas las partes que podían, también indirectamente, hacer entender que la guerra se había declarado por orden del rey.

Aún antes del inicio de las operaciones militares en la Liguria, desde Madrid se tomó otra importantísima decisión. Como se ha dicho, justo al mismo tiempo que el Consejo de Estado discutía sobre la concesión de la licencia a los Viejos, en una «Junta de presidentes» se afrontaba el tema del «desempeño». El resultado fue que, el 1 de septiembre, Felipe II procedía a firmar el decreto de suspensión de pagos a los mercaderes-banqueros por los asientos acordados desde noviembre del 1560 en adelante. Cuando, a primeros de octubre, la noticia se difundió tuvo el efecto de una verdadera bomba sobre la incandescente situación política genovesa. Viendo que se congelaban sus ingentes créditos justo en el momento en que se encontraban más duramente empeñados en el plano financiero a causa de su guerra privada contra la república, los Viejos se quedaron desconcertados. ¿Por qué una suspensión momentos después de haberse autorizado el conflicto? Parecía evidente que en Madrid alguien deseaba su ruina definitiva ${ }^{35}$.

Una vez más eran Felipe II y Antonio Pérez los únicos que tenían una visión completa de la situación. Al Consejo de Estado, y en especial al duque de

33 Cf. la «Relación de lo que el duque de Alva habló al nuncio y a los embaxadores del emperador y a los de Génova en Madrid a XXII de Octubre 1575 sobre las cosas de Génova», AGS, Estado 1405, ff. 129-131.

34 AGS, Estado 1072, f. 36.

35 Cf. DORIA, G.: Un quadriennio critico cit. 
Alba, le cogió por sorpresa la noticia de la suspensión de pagos. En una sesión del Consejo y de modo directo, Alba no dudó en declarar que jamás habría apoyado con tanta decisión la guerra si hubiera conocido la intención de la corona de bloquear los pagos a los mercaderes-banqueros ${ }^{36}$. Francisco de Garnica (que había tenido un papel fundamental en los trabajos de la "Junta de presidentes» y en la decisión de la bancarrota), afirmó que Alba no habría abogado con tanto ardor por la adopción de una línea política contraria a la del Papa si hubiera sabido lo que se estaba tratando en Roma: la renovación de las «tres gracias» (Subsidio, Excusado y Cruzada) ${ }^{37}$. Gregorio XIII llegó incluso a amenazar al rey con revocar dichas concesiones a causa de la guerra emprendida contra Génova.

Ante este panorama, da la impresión de que los consejos y las juntas funcionaban como compartimentos estancos, y de que Felipe II (junto con Antonio Pérez) actuaba como una especie de conductor de títeres a los que manipulaba mediante un pormenorizado control del flujo de las informaciones. Pero icon qué resultados? Guerra y suspensión de pagos parecían ser incompatibles. Los Viejos, privados de su crédito en todas las plazas financieras italianas y europeas, ya no eran capaces de sostener el costo de las operaciones militares. A mediados de octubre, Juan de Zúñiga describió el asalto de los depositarios y acreedores a los bancos genoveses en Roma y refirió las voces que circulaban sobre la quiebra del más rico y poderoso entre los mercaderes-banqueros ligures: Nicolò Grimaldi, llamado «el Monarca». Pero tampoco dejó de añadir que Felipe II había perdido igualmente el crédito y que era más pobre ahora, a pesar de disponer del dinero efectivo de las "consignaciones» secuestradas, que antes cuando le faltaba dinero pero tenía la plena confianza de los operadores financieros ${ }^{38}$.

Las contradicciones en las decisiones adoptadas por Felipe II resultaban evidentes. Había una guerra en curso y la bancarrota había dado al traste con los fondos necesarios para proseguirla. Al mismo tiempo, el recurso a las armas había suscitado la hostilidad del Papa lo que ponía en peligro los ingresos que la monarquía extraía de la tasación de los bienes eclesiásticos. El propio soberano se percató de esta compleja situación, y adjunta a la noticia de la suspensión de pagos envió a don Juan una categórica contraorden: «que si no huviere dado la licencia a los gentiles hombres viejos de Génova para mover las armas, que no se la dé, y que si se la huviere dado y no huvieren aún roto la guerra, que se la revoque, y que si huvieren començado, procure de que se concierten» ${ }^{39}$.

Los Viejos no pudieron hacer otra cosa que obedecer la orden de suspensión de las hostilidades. De este modo se había vuelto al punto de partida: la bús-

36 Verbal del Consejo de Estado del 28 de octubre de 1575, AGS, Estado 1405, ff. 141-142.

37 «Lo que parece al contador Garnica sobre lo de Génova haviendo visto los despachos que se vieron en Consejo de Estado y entendido lo que ally paresció", del 3 de enero de 1576, AGS, Estado 1408, f. 230.

38 Carta a Felipe II del 9 de octubre de 1575, AGS, Estado 925, f. 205.

39 AGS, Estado 925, f. 210 
queda de un acuerdo en la mesa de negociaciones. El compromiso se alcanzó con las Leges Novae de marzo de 1576, fruto de la obra de los ministros delegados de tres príncipes (el Papa, el Emperador y el rey de España) y de la cuidadosa dirección del cardenal Giovanni Morone. La república recibía del exterior su nueva constitución, destinada a durar más de dos siglos.

Uno más de entre los efectos paradójicos de la política de Felipe II, y al mismo tiempo de los desconcertantes mecanismos en la toma de decisión de su Corte, fue la momentánea parálisis del aparato militar español en Italia por falta de fondos. Recurrir al crédito era imposible, por lo que don Juan comunicó que no sería capaz de mover la flota ni de reclutar soldados hasta la llegada por mar del dinero efectivo de las consignaciones secuestradas. Se abrió así, desde mediados de octubre, un periodo de tiempo de más o menos dos meses en el que una posible intervención armada de Francia o de uno de los potentados italianos en Génova no hubiera podido encontrar una oposición efectiva por parte de las fuerzas del Rey Católico ${ }^{40}$. Las grandes visiones estratégicas, aunque fueran fruto de una larga elaboración y estuvieran claras en sus líneas de fondo, como lo era la idea de que el imperio español no podía prescindir de Génova, encontraban grandes dificultades a la hora de traducirse en decisiones políticas concretas. Grandes estrategias y pequeñas intrigas cortesanas se entrelazaban en la determinación de los destinos de la monarquía.

40 Cf. las cartas de Juan de Austria a partir de octubre de 1575 en AGS, Estado 1067 y 1072.

Hispania, LXV/1, núm. 219 (2005) 21-44 